\title{
PL Property of Al-N Codoped p-type ZnO Thin Films Fabricated by DC Magnetron Sputtering
}

\author{
Yan-Yan Liu, Hu-Jie Jin, and Choon-Bae Park* \\ School of Electrical Electronic and Information Engineering, Wonkwang University, WRISS, 344-2 Shinyong. \\ dong, Iksan-si, Chonbuk 570-749, Republic of Korea \\ Geun C. Hoang \\ Department. of Semiconductor and Display, Wonkwang University, WRISS, 344-2 Shinyongudong. Iksan-si, \\ Chonbuk 570-749, Republic of Korea
}

(Received May 132009 , Accepted June 17 2009)

\begin{abstract}
High-quality Al-N doped p-type $\mathrm{ZnO}$ thin films were deposited on Si and buffer layer/Si by DC magnetron sputtering in a mixture of $\mathrm{N}_{2}$ and $\mathrm{O}_{2}$ gas. The target was ceramic $\mathrm{ZnO}$ mixed with $\mathrm{Al}_{2} \mathrm{O}_{3}(2 \mathrm{wt} \%$ ). The p-type $\mathrm{ZnO}$ thin films showed a carrier concentration in the range of $1.5 \times 10^{15} \sim 2.93 \times 10^{17} \mathrm{~cm}^{-3}$, resistivity in the range of $131.2 \sim 2.864 \Omega \mathrm{cm}$, mobility in the range of $3.99 \sim 31.6 \mathrm{~cm}^{2} \mathrm{~V}^{-1} \mathrm{~s}^{-1}$, respectively. It was easier to dope p-type $\mathrm{ZnO}$ films on $\mathrm{Si}$ substrates than on buffer layer/Si. The film grown on $\mathrm{Si}$ showed the highest quality of photoluminescence (PL) characteristics. The $\mathrm{Al}$ donor energy level depth $\left(\mathrm{E}_{\mathrm{d}}\right)$ of $\mathrm{Al}-\mathrm{N}$ codoped $\mathrm{ZnO}$ films was reduced to about $50 \mathrm{meV}$, and the $\mathrm{N}$ acceptor energy level depth $\left(\mathrm{E}_{\mathrm{a}}\right)$ was reduced to $63 \mathrm{meV}$.
\end{abstract}

Keywords: P-type ZnO film, Buffer layer, DC magnetron sputtering, Photoluminescence, Acceptor/donor level

\section{INTRODUCTION}

$\mathrm{ZnO}$ has attracted substantial interest in the area of photoelectronic devices for the potential high performance of light-emission properties, because $\mathrm{ZnO}$ has a large exciton binding energy of $60 \mathrm{meV}$ and direct wide electron energy bandgap of $3.37 \mathrm{eV}$ at room temperature (RT). It is pivotal to grow high quality p-type $\mathrm{ZnO}$ films to implement lightemitting devices based on $\mathrm{ZnO}$ material. Many approaches (with various dopants) have been used to fabricate high quality p-type $\mathrm{ZnO}$ films[1-7]. In theory, group I and group V elements can be used as acceptor dopants for mono-doping in $\mathrm{ZnO}$, and $\mathrm{N}$ is the best dopant of group $\mathrm{V}$ elements[8]. However, it is difficult to obtain high quality p-type $\mathrm{ZnO}$ using mono-doping with these elements. Hydrogen is affiliated to group I elements and acts as a donor in $\mathrm{ZnO}$ [9]. Because of the electron compensation induced by interstitial zinc $\left(\mathrm{Zn}_{\mathrm{i}}\right)$ and oxygen vacancy $\left(\mathrm{V}_{\mathrm{o}}\right)$, low acceptor solubility and deep acceptor levels, it is difficult to obtain p-type $\mathrm{ZnO}$ using the mono-doping method with group I and group $\mathrm{V}$ elements as dopants. T. Yamamoto et al. proposed the theory of codoping group $\mathrm{V}$ and III elements with a ratio of $2: 1$ (which can increase acceptor solubility and make acceptor levels shallower) to solve the problems of p-type doping in $\mathrm{ZnO}[10,11]$. The feasibility of codoping theory has been proven through experiments[12-15]. Magnetron sputtering is often used to grow thin films for the ease of operation and is also used to grow p-type $\mathrm{ZnO}$ films. DC and RF magnetron sputtering have been used to grow intrinsic p-type $\mathrm{ZnO}$ films[16] and doped p-type $\mathrm{ZnO}$ films[17-21]. According to codoping theory, deep acceptor and donor levels can be made shallower, and the low solubility of acceptors in $\mathrm{ZnO}$ is enhanced by reducing Madelung energy. To date, explicit

\footnotetext{
*Author to whom corresponding should be addressed: electronic mail: cbpark@wonkwang.ac.kr
}

evidence of improving the deep acceptor level (i.e. making it shallower by codoping) cannot be seen in the literature. When ceramic $\mathrm{ZnO}$ is used as the sputtering target, it is hard to fabricate p-type $\mathrm{ZnO}$ films in the mixture of $\mathrm{N}_{2}$ and $\mathrm{O}_{2}$ gas by RF magnetron sputtering, despite the high crystallinity shown in X-ray diffraction (XRD) spectra. This study confirmed that both acceptor levels and donor levels were made shallower.

\section{EXPERIMENT}

Al-N codoped $\mathrm{ZnO}$ films were fabricated on $\mathrm{Si}$ and $\mathrm{Si}$ coated with a buffer layer (buffer layer/Si) by DC magnetron sputtering. All Si substrates were ultrasonically cleaned sequentially in acetone, methanol, and then DI water. Later they were dried by $\mathrm{N}_{2}$ gas. The ceramic $\mathrm{ZnO}$ mixed with $2 \mathrm{wt} \% \mathrm{Al}_{2} \mathrm{O}_{3}$ was selected as a sputtering target. The details for deposition and annealing buffer layer and Al-N codoped $\mathrm{ZnO}$ films are listed in Table 1. In-situ annealing was carried out on the buffer layer templates to decrease resistivity and promote crystallinity. The annealing gas, temperature, pressure, and time were $\mathrm{O}_{2}, 800{ }^{\circ} \mathrm{C}, 15$ mTorr and $20 \mathrm{~min}$, respectively. XRD, Hall Effect in Van der Pauw configuration and photoluminescence (PL) were conducted to evaluate the microstructure, electrical, and optical properties.

\section{RESULTS AND DISCUSSION}

Figure 1 shows that all films have c-axis orientation. Two theta diffraction (002) peaks lie at the position smaller than the unstressed position of $34.44^{\circ}$ (dotted line), implying that the c-axis crystal lattice constant of $\mathrm{Al}-\mathrm{N}$ codoped $\mathrm{ZnO}$ 
Table 1. Growth conditions of a homo-buffer layer template and $\mathrm{Al}-\mathrm{N}$ codoped $\mathrm{ZnO}$ films.

\begin{tabular}{cccc}
\hline \hline \multicolumn{2}{c}{ Buffer layer } & \multicolumn{2}{c}{ Al-N codoped ZnO thin film } \\
\hline parameters & conditions & parameters & conditions \\
\hline target & $\mathrm{ZnO}(5 \mathrm{~N})$ & target & $\mathrm{AZO}(5 \mathrm{~N})$ \\
substrate & $\mathrm{n}$-type $(100) \mathrm{Si}$ & substrate & $\mathrm{n}-(100) \mathrm{Si}$, buffer layer $/ \mathrm{Si}$ \\
base pressure & $7 \times 10^{-6} \mathrm{Torr}$ & base pressure & $7 \times 10^{-6} \mathrm{Torr}$ \\
working pressure & $15 \mathrm{mTorr}$ & working pressure & $6,15 \mathrm{mTorr}$ \\
RF power & $120 \mathrm{~W}$ & DC power & $340 \mathrm{~V} \mathrm{x} \mathrm{0.1} \mathrm{A}$ \\
growth temperature & $100{ }^{\circ} \mathrm{C}$ & growth temperature & $450^{\circ} \mathrm{C}$ \\
ambient gases & $\mathrm{Ar}: \mathrm{O}_{2}=4: 1(5 \mathrm{~N})$ & ambient gases & $\mathrm{N}_{2}: \mathrm{O}_{2}=1: 4,2: 3,3: 2,4: 1$ \\
pre-sputtering time & $10 \mathrm{~min}$ & pre-sputtering time & $10 \mathrm{~min}$ \\
growth time & $30 \mathrm{~min}(70 \mathrm{~nm})$ & growth time & $120 \mathrm{~min}(570 \mathrm{~nm})$ \\
\hline \hline
\end{tabular}

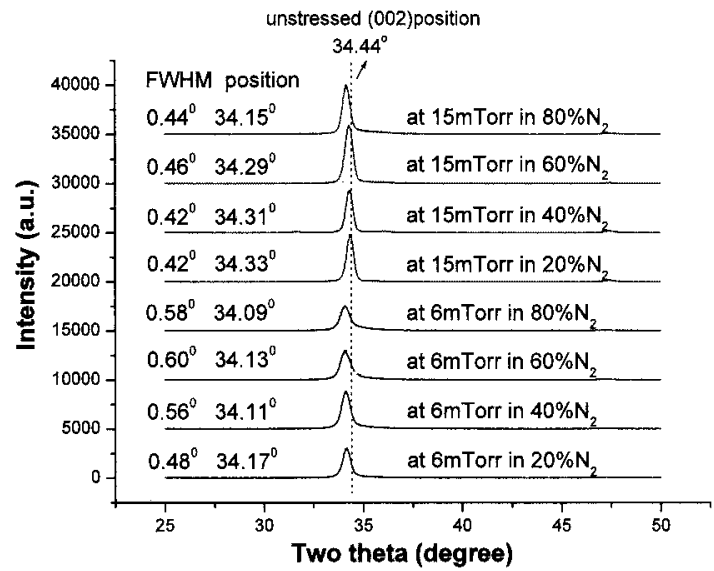

(a)

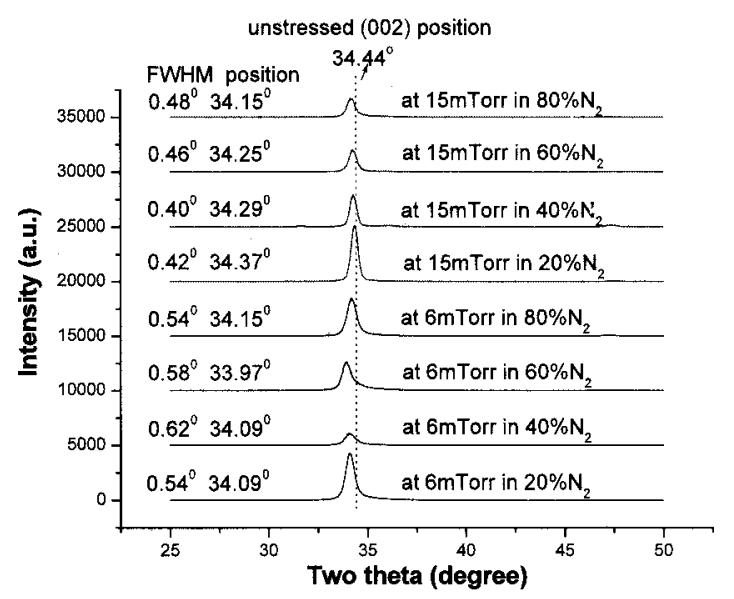

(b)

Fig. 1. XRD patterns of Al-N codoped $\mathrm{ZnO}$ thin films deposited on (a) $\mathrm{Si}$, (b) buffer layer/Si in different $\mathrm{N}_{2}$ fractions.

film is larger than that of the single crystal bulk $\mathrm{ZnO}$. This is a result of the molecular $\mathrm{N}_{2}$ doping in $\mathrm{ZnO}$ [22]. The position of (002) peaks shows that the films grown at 15 mTorr show a closer crystal c-axis lattice constant to the corresponding lattice constant of bulk $\mathrm{ZnO}$ than other films. The peak positions of films grown at $6 \mathrm{mTorr}$ lie at the lower positions than those at $15 \mathrm{mTorr}$ in the same $\mathrm{N}_{2}$ fraction, implying the incorporation of more molecular $\mathrm{N}_{2}$ in films grown at $6 \mathrm{mT}$ Torr. The FWHMs of $(002)$ peaks at 6 mTorr are larger than those at $15 \mathrm{mTorr}$, indicating that average grain sizes of the films grown at 6 mTorr are smaller than those at 15 mTorr. Figure 1(a) shows that the intensity of the (002) peak of $\mathrm{ZnO}$ films grown on $\mathrm{Si}$ substrates at the $15 \mathrm{mT}$ Torr is higher than that at $6 \mathrm{mTorr}$. Figure 1(b) shows the (002) peak intensity of films deposited on buffer layer/Si, not showing evident changes compared with Fig. 1(a). Usually, a buffer layer is beneficial to the crystallinity and microstructure of $\mathrm{ZnO}$ film, but in the case of Al-N codoped $\mathrm{ZnO}$ films deposited by DC magnetron sputtering in this study, the buffer layer does not show the improvement of the $\mathrm{ZnO}$ microstructure via XRD spectra.

The films were measured by the Hall Effect in Van der Pauw configuration to evaluate the electrical properties. Table 2 lists the electrical property for the films grown at 15 mTorr in different $\mathrm{N}_{2}$ fractions. Sample S1, BS1, and BS3 had high resistivity $\left(>1 \times 10^{5} \Omega \mathrm{cm}\right.$ ) which was beyond the measurement range of the Hall effect analyser and the measurements of their electrical properties were not possible. All Al-N codoped $\mathrm{ZnO}$ films on $\mathrm{Si}$ substrates show p-type conduction. When the films were grown on a buffer layer/Si, the conduction type was changed from ntype to p-type with an increasing $\mathrm{N}_{2}$ fraction in ambient conditions. The p-type film (BS4) grown on buffer layer $/ \mathrm{Si}$ shows the highest hole concentration of $2.93 \times 10^{17} \mathrm{~cm}^{-3}$ and low hole mobility of $3.99 \mathrm{~cm}^{2} \mathrm{~V}^{-1} \mathrm{~s}^{-1}$. The n-type film (BS2) grown on buffer layer/Si shows a low electron concentration of $1.19 \times 10^{16} \mathrm{~cm}^{-3}$ and a high mobility of 142 $\mathrm{cm}^{2} \mathrm{~V}^{-1} \mathrm{~s}^{-1}$.

Three films (sample S2, S3, and S4) grown on Si at 15 mTorr show p-type conduction and the changing tendencies of the electrical properties are shown in Fig. 2 . The p-type film (S3) grown in $\mathrm{N}_{2}$ fraction of $60 \%$ shows the highest hole concentration of $9.35 \times 10^{16} \mathrm{~cm}^{-3}$ and the lowest resistivity of $2.864 \Omega \mathrm{cm}$ and moderate mobility of 23.3 $\mathrm{cm}^{2} \mathrm{~V}^{-1} \mathrm{~s}^{-1}$. The hole concentration was reduced and resistivity was increased for p-type $\mathrm{ZnO}$ film grown on $\mathrm{Si}$ when it was fabricated in $\mathrm{N}_{2}$ fraction of $20 \%$ or $80 \%$.

PL spectra of sample BS2, BS4, and $\mathrm{S} 4$ at $6 \mathrm{~K}$ are shown in Fig. 3(a), (c), and (e), respectively. The corresponding high-resolution spectra near the band edge (3.15-3.5 eV) are shown in Fig. 3(b), (d) and (f), respectively. The n-type film (BS2) grown on buffer layer/Si in N2 fraction of $40 \%$ shows many deep defect levels at $1.69,1.77,2.09$, and 2.73 eV (Fig. 3(a)) and near the band edge levels at 3.363 and $3.304 \mathrm{eV}$ (Fig. 3(b)). The peaks of 3.363 and $3.304 \mathrm{eV}$ are 
Table 2. Electrical properties of Al-N codoped $\mathrm{ZnO}$ films grown on $\mathrm{Si}$ and buffer layer/Si substrates at $15 \mathrm{mTorr}$ in different $\mathrm{N}_{2}$ fractions.

\begin{tabular}{ccccccc}
\hline \hline sample & substrate & $\begin{array}{c}\text { condition } \\
\left(\mathrm{N}_{2} \text { fraction }\right)\end{array}$ & type & $\begin{array}{c}\text { concentration } \\
\left(10^{16} \mathrm{~cm}^{-3}\right)\end{array}$ & $\begin{array}{c}\text { mobility } \\
\left(\mathrm{cm}^{2} \mathrm{~V}^{-1} \mathrm{~s}^{-2}\right)\end{array}$ & $\begin{array}{c}\text { resistivity } \\
(\Omega \mathrm{cm})\end{array}$ \\
\hline $\mathrm{S} 1$ & $\mathrm{Si}$ & $20 \%$ & -- & -- & -- & - \\
$\mathrm{S} 2$ & $\mathrm{Si}$ & $40 \%$ & $\mathrm{p}$ & 0.15 & 31.6 & 131.2 \\
$\mathrm{~S} 3$ & $\mathrm{Si}$ & $60 \%$ & $\mathrm{p}$ & 9.35 & 23.3 & 2.864 \\
$\mathrm{~S} 4$ & $\mathrm{Si}$ & $80 \%$ & $\mathrm{p}$ & 8.82 & 22.6 & 3.128 \\
$\mathrm{BS} 1$ & Buffer layer/Si & $20 \%$ & -- & -- & -- \\
$\mathrm{BS} 2$ & Buffer layer/Si & $40 \%$ & $\mathrm{n}$ & 1.19 & 142 & -- \\
$\mathrm{BS} 3$ & Buffer layer/Si & $60 \%$ & -- & -- & -- & 3.689 \\
$\mathrm{BS} 4$ & Buffer layer/Si & $80 \%$ & $\mathrm{p}$ & 29.3 & 3.99 & -- \\
\hline \hline
\end{tabular}

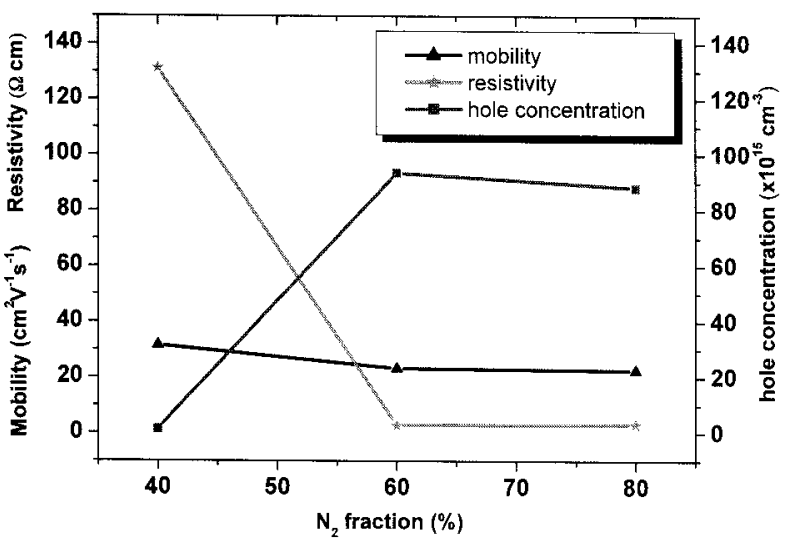

Fig. 2. Electrical property of $\mathrm{Al}-\mathrm{N}$ codoped $\mathrm{ZnO}$ thin films deposited on $\mathrm{Si}$ at $15 \mathrm{mTorr}$ in different $\mathrm{N}_{2}$ fractions.

attributed to the transition of excitons bound to the neutral donor $\left(\mathrm{D}^{\circ} \mathrm{X}\right)$ and transition of donor-acceptor pair (DAP) respectively. The p-type film (BS4) grown on buffer layer/Si in N2 fraction of $80 \%$ shows deep defect levels at 1.67, 2.36, 2.59, and $2.95 \mathrm{eV}$ (Fig. 3(c)) and near band edge levels at 3.374 and $3.323 \mathrm{eV}$ (Fig. 3(d)). The peaks of 3.374 and $3.323 \mathrm{eV}$ are attributed to the transition of free electrons in the conduction band to acceptor level (FA) and DAP respectively. The p-type film (S4) grown on $\mathrm{Si}$ in $\mathrm{N}_{2}$ fraction of $80 \%$ shows deep defect levels at 1.66, 2.36, 2.57, and $2.76 \mathrm{eV}$ (Fig. 3(e)) and near band edge levels at 3.366 and $3.316 \mathrm{eV}$ (Fig. 3(f)). The peaks of 3.366 and $3.316 \mathrm{eV}$ are attributed to FA and DAP respectively. The small peaks ranged from 3.17 to $3.27 \mathrm{eV}$ and are related to $\mathrm{Al}-\mathrm{N}$ uncoupled DAPs as shown in Fig. 3(b), (d) and (f).

The emission energy of DAP at low temperature is

$$
h w=E_{E}-E_{a}-E_{d}+\frac{e^{2}}{4 \pi r r}
$$

where, $E_{g}, E_{a}, E_{d}$, e, $\varepsilon$ and $r$ are energy bandgap, acceptor level to valence band maximum, donor level to conduction band minimum, electron charge, permittivity, and distance between the acceptor and donor, respectively. According to the formula (1), the emitting energy hv increases with decreasing distance $\mathbf{r}$. Suppose that the donor density exists in the given range for all films, the higher the acceptor concentration is, the shorter the distance is. Thereby, the photon energy emitting from DAP of the film with high acceptor concentration is increased. The hole concentration of the film (S4) on Si is lower than that of the film (BS4) on buffer layer/Si. The emissions from FA and DAP of the film (BS4) on the buffer layer are larger than the corresponding emissions from that (S4) on $\mathrm{Si}$.

The emission energy of FA at low temperature is

$$
w=E_{\mathrm{g}}-E_{\mathrm{g}}
$$

The peak energy difference between DAP and FA is the depth of donor level $\left(E_{d}\right)$. The donor levels of sample BS4 and $\mathrm{S} 4$ are $51 \mathrm{meV}$ and $50 \mathrm{meV}$, respectively. $M$. Grundmann et. al claimed that the depth of Al donor level in Al-doped $\mathrm{ZnO}$ is $65 \mathrm{meV}$ [23]. In this study, the $\mathrm{Al}$ donor level was reduced by $15 \mathrm{meV}$. The DAP and FA peaks of the film (BS4) with higher hole concentration(Fig. 3(d)) have a blue shift compared to that (S4) with lower hole concentration (Fig. 3(f)). This may be caused by the enlargement of bandgap in the film with high internal stress[24].

Excitons bound to neutral acceptors $\left(\mathrm{A}^{0} \mathrm{X}\right)$ are usually shown in the photon energy range of 3.3-3.5 eV[25,26]. In this study, the peaks of 3.366 and $3.374 \mathrm{eV}$ are beyond this range. So the two peaks in this study are not attributed to the recombination of $\mathrm{A}^{\circ} \mathrm{X}$. The peak of $3.366 \mathrm{eV}$ of the film on the buffer layer and $3.374 \mathrm{eV}$ of the film on Si may be attributed to the recombination of free electrons in the conduction band and holes at the acceptor level (FA). The bandgap energy of $\mathrm{ZnO}$ at low temperature is about 3.437 eV[27]. According to formula (2) and the value of $\mathrm{ZnO}$ bandgap energy, the acceptor levels of sample BS4 and S4 are $63 \mathrm{meV}$, and $71 \mathrm{meV}$, respectively, less than 100 $\mathrm{meV}[28]$. In this study, $\mathrm{Al}$ donor level and $\mathrm{N}$ acceptor level were reduced by $15 \mathrm{meV}$ and $37 \mathrm{meV}$, respectively, which is beneficial to the formation of $\mathrm{p}$-type conduction.

\section{CONCLUSION}

$\mathrm{Li}\left[\mathrm{Ni}_{0.2} \mathrm{Li}_{0.2} \mathrm{Mn}_{0.6}\right] \mathrm{O}_{2}$ cathode powder was synthesized via the microwave assisted sol-gel process. The XRD study of the material has confirmed that an $\mathrm{O} 3$ layered structure formed during a microwave treatment that followed a heating process. The electrochemical test of the sample has shown that it has a high discharge capacity and stable cyclic 


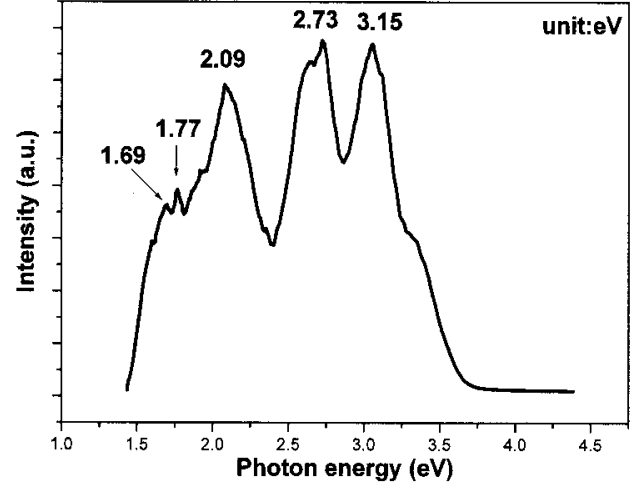

(a)

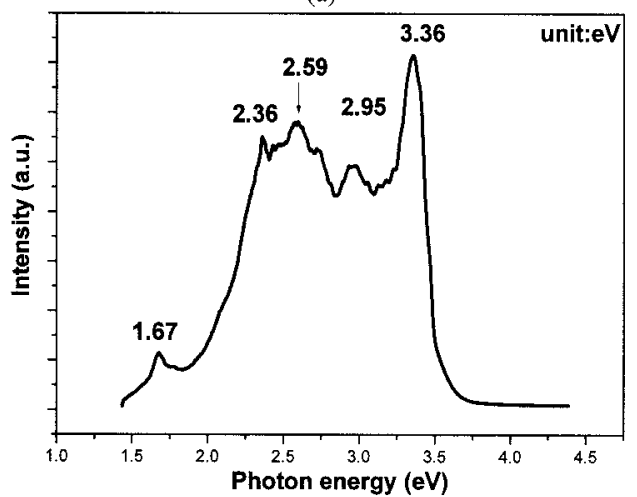

(c)

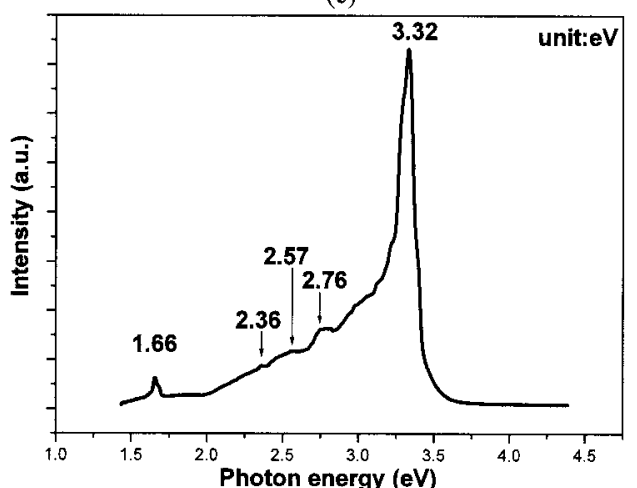

(e)

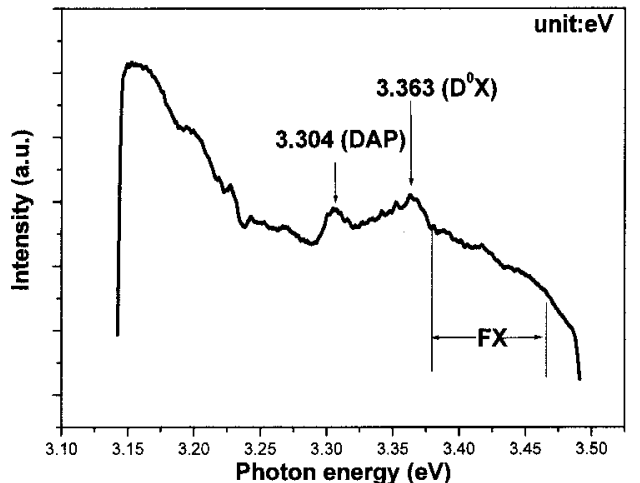

(b)

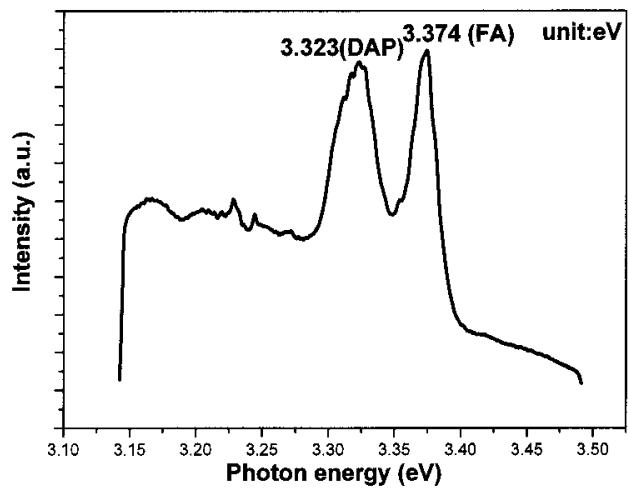

(d)

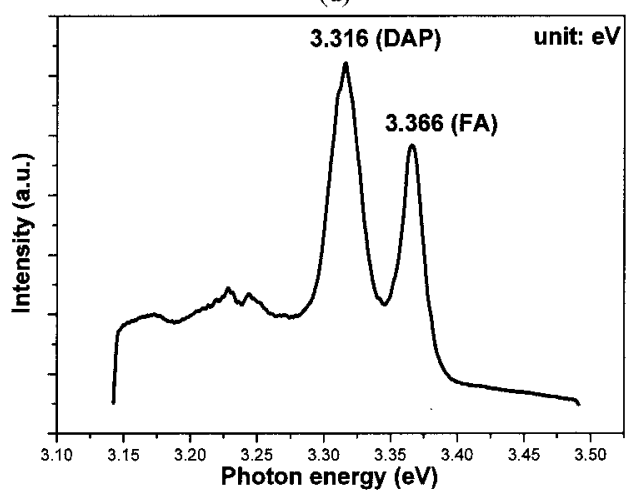

(f)

Fig. 3. PL spectra at $6 \mathrm{~K}$ in full regions of Al-N codoped $\mathrm{ZnO}$ films deposited at $15 \mathrm{mTorr}$ on $\mathrm{Si}$ and buffer layer/Si substrates in a different $\mathrm{N} 2 \mathrm{fraction}$. (a) buffer layer/Si, $\mathrm{N}_{2}: 40 \%$, (c) buffer layer $/ \mathrm{Si}, \mathrm{N}_{2}: 80 \%$, and (e) $\mathrm{Si}, \mathrm{N}_{2}: 80 \%$, and their corresponding high-resolution spectra near the band edge are shown in (b), (d) and (f), respectively.

properties. The discharge capacity of the sample electrode was $230 \mathrm{mAhg}^{-1}$ at the specific current of $40 \mathrm{mAg}^{-1}(0.2 \mathrm{C}$ rate) in the voltage range of $2.0 \sim 4.8 \mathrm{~V}$. It was saturated to $\sim 200 \mathrm{mAhg}^{-1}$ after 30 cycles. The discharge capacity decreased to $\sim 140 \mathrm{mAhg}^{-1}$ at $6 \mathrm{C}\left(1200 \mathrm{mAg}^{-1}\right)$ rate, but the cyclic performance did not deteriorate at a high $\mathrm{C}$ rate.

\section{REFERENCES}

[1] S.-J. Bao, Y.-Y. Liang, and H.-L. Li, Mater. Lett. 59, 3761 (2005).

[2] M. Nakayama, K. Watanabe, H. Ikuta, Y. Uchimoto, and M. Wakihara, Solid State Ionics 164, 35 (2003).

[3] H. Yan, X. Huang, H. Li, and L. Chen, Solid State Ionics 11, 113 (1998).

[4] P. Kalyani, N. Kalaiselvi, and N. G. Renganathan, J. Power Sources
$123,53(2003)$.

[5] S.-J. Bao, Y.-Y. Liang, W.-J. Zhou, B.-L. He, and H.-L. Li, J. Power Sources 154, 239 (2006)

[6] Y.-P. Fu, C.-H. Lin, Y.-H. Su, and S.-H. Wu, J. Power Sources 159, $215(2006)$.

[7] K. S. Park, J. T. son, H. T. Chung, S. J. Kim, C. H. Lee, and H. G. Kim, Electrochem. Commun. 5, 839 (2003).

[8] J. H. Ryu, S. B. Kim, and Y. J. Park, J. of KIEEME(in Korean) 21, 249 (2008).

[9] Y. J. Park, Y.-S. Hong, X. Wu, K. S. Ryu, and S. H. Chang, J. Power Sources 129, 288 (2004).

[10] Y. J. Park, J. of KIEEME(in Korean) 20, 443 (2007).

[11] J. H. Ryu, B. G. Park, S. B. Kim, and Y. J. Park, J. Appl. Electrochem. 39, 1059 (2009).

[12] Y. Xia, M. Yoshio, and H. Noguchi, Electrochim. Acta, 52, 240 (2006).

[13] J.-S. Kim, C. S. Johnson, J. T. Vaughey, S. A. Hackney, K. A. Walz, W. A. Zeltner, M. A. Anderson, and M. M. Thackeray, J. Electrochem. Soc. 151, A1755 (2004). 